EDITORIAL

\title{
Recent advances in applied optimization under uncertainty
}

\author{
Stein-Erik Fleten ${ }^{1} \cdot$ Rüdiger Schultz ${ }^{2}$
}

Published online: 19 July 2021

(C) The Author(s), under exclusive licence to Springer-Verlag GmbH Germany, part of Springer Nature 2021

Optimization under uncertainty, or stochastic programming, is a framework for developing and solving large-scale optimization problems that support sequential decision making with explicit consideration of randomness between decisions. This topical collection consists of recent applications of the field. This includes two papers from this journal's special issue of the 2019 International Conference on Stochastic Programming in Trondheim, Norway, as well as four other papers exploring portfolio selection, hydropower reservoir management and a more methodology-oriented paper that deals with endogenous uncertainty. The special issue is edited by Francesca Maggioni, Stein-Erik Fleten and David Wozabal.

Publisher's Note Springer Nature remains neutral with regard to jurisdictional claims in published maps and institutional affiliations.

Stein-Erik Fleten

Stein-Erik.Fleten@ntnu.no

1 Norwegian University of Science and Technology, Gløshaugen, Norway 7491

2 University of Duisburg-Essen, Duisburg, Germany 47057 